\title{
Reduced Lean Body Mass and Cardiometabolic Diseases in Adult Males with Overweight and Obesity: A Pilot Study
}

\author{
Shirine Khazem ${ }^{1}$, Leila Itani ${ }^{1}$, Dima Kreidieh ${ }^{1}$, Dana El Masri ${ }^{1}$, Hana Tannir ${ }^{1}$, \\ Roberto Citarella ${ }^{2}$ and Marwan El Ghoch ${ }^{1,3, *}$ \\ 1 Department of Nutrition and Dietetics, Faculty of Health Sciences, Beirut Arab University, \\ P.O. Box 11-5020 Riad El Solh, Beirut 11072809, Lebanon; shirine_sk@live.com (S.K.); \\ l.itani@bau.edu.lb (L.I.); d.kraydeyeh@bau.edu.lb (D.K.); dana.masri@bau.edu.lb (D.E.M.); \\ hana.tannir@bau.edu.lb (H.T.) \\ 2 CTR Centre of Rehabilitation Therapy, Via Fratelli Cervi, 59/e, 42124 Reggio Emilia, Italy; citarella@ctr-re.it \\ 3 Nutrition and Dietetics Program-CTR Centre of Rehabilitation Therapy, Via Fratelli Cervi, 59/e, \\ 42124 Reggio Emilia, Italy \\ * Correspondence: m.ghoch@bau.edu.lb or marwan1979@hotmail.com; \\ Tel.: +961-1-300110 (ext. 2332) or +39-0522-385411; Fax: +39-0522-385473
}

Received: 6 November 2018; Accepted: 4 December 2018; Published: 5 December 2018 updates

\begin{abstract}
Little is known about the reduction in lean body mass (LBM) and its health consequences in overweight and in obesity, especially in males. Therefore, we aimed to assess the prevalence of low LBM in treatment-seeking adult males with overweight and obesity and the association with cardiometabolic diseases, i.e., type 2 diabetes, cardiovascular diseases and dyslipidemia. A body composition assessment was conducted by a bio-impedance analyzer (InBody 170) among a total of 110 males, of whom 72 were overweight and obese and were referred to the Outpatient Clinic in the Department of Nutrition and Dietetics at Beirut Arab University (BAU) in Lebanon, and 38 were normal-weight participants of similar ages. The participants with overweight and obesity were then categorized as being with or without low LBM. Of the sample of 72 participants, $50(69.4 \%)$ met the criteria for reduced LBM and displayed a significantly higher prevalence of cardiometabolic diseases (i.e., type 2 diabetes, cardiovascular diseases and dyslipidemia) than those with normal LBM $(36.0 \%$ vs. $9.1 \% ; p=0.019)$. Logistic regression analysis showed that low LBM increases the odds of having cardiometabolic diseases by nearly $550 \%$ (odds ratio (OR) $=5.46,95 \%$ confidence interval $(\mathrm{CI})=1.31-26.39, p<0.05)$ after adjusting for total fat and central adiposity. Treatment-seeking adult males with overweight and obesity displayed a great prevalence of reduced LBM, which seems to be strongly associated with cardiovascular and metabolic diseases.
\end{abstract}

Keywords: lean body mass; obesity; type 2 diabetes; metabolic syndrome; cardiometabolic diseases

\section{Introduction}

Extensive research has been conducted on body composition patterns in obesity [1]; however, most studies have focused on fat body mass and there is a lack of data on the reduction in lean body mass (LBM) as a primary outcome and its consequences for health among this population, especially in males [2]. This is an important limitation in the field, since, in the general population, low LBM has been shown to be associated with a higher risk of cardiovascular events [3], diabetes [4], metabolic syndrome [5], longer hospitalization [6], and mortality [7,8].

Recent, well-designed studies have underlined the association between low LBM and cardiometabolic risk factors in females with or without obesity [9-11]. However, these results cannot be generalized 
across genders and therefore should still be considered preliminary. To the best of our knowledge, there is a lack of data derived from males who are overweight or suffer obesity in this regard. Therefore, the identification of low LBM and its consequence on health outcomes in this population is of critical importance, with the application of potential therapeutic strategies (e.g., physical activity interventions, high-protein diets and protein supplements) focused on limiting LBM deterioration as a clinical priority [12].

On the other hand, it is important to note that defining low LBM in individuals with excess weight based only on lean mass (without accounting for body mass) may be misleading, because patients with overweight and obesity tend to have a relatively high lean mass [13]. Hence, the criteria for low LBM, when based solely on this parameter, may not be met among these individuals in whom the prevalence may therefore be greatly underestimated [13].

The aims of the present study were, firstly to assess the prevalence of low LBM in treatment-seeking adult males with overweight and obesity by applying three different definitions, which, in addition to appendicular lean mass (ALM), also involve body size (weight and body mass index (BMI)) [14-16]. The second aim was to compare which of these three definitions is more clinically useful for detecting any potential association between low LBM and cardiovascular and metabolic diseases, namely, type 2 diabetes, cardiovascular diseases and dyslipidemia in this population.

\section{Materials and Methods}

Participants were selected from a cohort of 335 patients seeking treatment at the Beirut Arab University (BAU) nutritional and weight management outpatient clinic in the Department of Nutrition and Dietetics of BAU in Beirut, Lebanon, between 2017 and 2018. Recruitment was possible following consecutive referrals to the clinic and only male patients were considered eligible. A total of 72 males out of the 111 assessed for eligibility were included because they fulfilled the inclusion criteria for being aged $\geq 18$ years, with a BMI $\geq 25.0 \mathrm{~kg} / \mathrm{m}^{2}$ and at least one weight loss-responsive co-morbidity (i.e., type 2 diabetes, cardiovascular disease, etc., two or more risk factors), as defined by the Adult Treatment Panel III [17]. Patients who were on medication that affect body weight and/or body composition or who were affected by diseases associated with weight loss or severe psychiatric disorders were excluded. The power analysis for the sample size was conducted retrospectively based on the probability of having cardiometabolic diseases when exposed/unexposed to reduced lean body mass and the corresponding odds in the study sample. Using G power post hoc computation of achieved power given an $\alpha=0.05$ and odds ratio of 5.6 from cross tabulation and assuming a moderate association with covariates $\left(R^{2}=0.25\right.$ ), a sample of 72 cases would give a power of $88 \%$ (having a $12 \%$ chance of rejecting $\mathrm{H}_{0}$ when it is true/or having a false positive) [18].

Thirty-eight normal-weight male participants (BMI $\geq 18.5$ and $<25 \mathrm{~kg} / \mathrm{m}^{2}$ ) were recruited from university listservs and advertisements. All were healthy and weight-stable with no history of cardiometabolic diseases or other significant medical conditions and having no current medication intake. The study design was reviewed and approved by the Institutional Review Board of BAU (No. 2018H-0050-HS-R-0293), and all participants gave informed written consent for the anonymous use of their personal information.

A questionnaire was administered to participants with overweight and obesity and controls in order to retrieve information regarding their medical history and demographic and social conditions (age, marital status etc.).

Body weight and height were measured by a dietician affiliated with the study using a weighing scale (SECA 2730-ASTRA, Germany) and medical stadiometer respectively. Each participant's BMI was then calculated as per the standard formula of body weight $(\mathrm{kg})$ divided by height $(\mathrm{m})$ squared.

A bioimpedance analyzer (InBody 170, BIOSPACE, China) was used to measure the body composition. It provides separate body mass readings for different segments of the body and uses an algorithm incorporating impedance, age and height in order to estimate total and regional body fat and fat-free mass. A dietician affiliated with the study and with information based on a clinical 
assessment ensured that participants were normally hydrated and had abstained from drinking (i.e., consuming caffeine or alcohol) and exercising for at least $12 \mathrm{~h}$ before the test. The total fat and lean mass percentages and the Appendicular Lean Mass (ALM) were calculated using standard formulas [19].

Low LBM was defined by means of three definitions as follows:

(1) Batsis et al. [14]: ALM/BMI $<0.789$

(2) Levine and Crimmins [15]: (ALM/weight) $\times 100 \%<25.72$

(3) Oh et al. [16]: (ALM/weight) $\times 100 \%<29.60$

Cardiovascular and metabolic disease in this study indicates the presence of any diseases such as type 2 diabetes, cardiovascular diseases (coronary heart disease, stroke, transient ischemic attack, and peripheral arterial disease) and dyslipidemia (a decreased concentration of high-density lipoprotein cholesterol, and an increased concentration of high-density lipoprotein cholesterol and triglycerides) based on self-reported diagnosis, either simultaneously or separately.

Descriptive statistics were calculated as means, standard deviation, frequencies, and proportions. The $\chi^{2}$ test and student's $t$-test were used to compare proportions and means, respectively, between participants with normal weight and those with overweight and obesity, and between participants with and without low LBM in the clinical sample. Simple and multiple logistic regression analyses were performed to calculate the odds of the presence of cardiometabolic diseases in the clinical sample with low LBM. The data were tested by a quantile-quantile normality plot, which revealed that variables were normally distributed. All analyses were performed using SPSS version 25.0 (IBM Corp.; IBM, Armonk, NY, USA). Statistical significance was considered at $p<0.05$.

\section{Results}

Table 1 shows the sociodemographic characteristics of the two study sample groups that comprised of 110 males: 72 participants with overweight or obesity (mean BMI of $33.69 \pm 5.85 \mathrm{~kg} / \mathrm{m}^{2}$ ) and 38 participants with normal weight (mean BMI of $22.31 \pm 1.83 \mathrm{~kg} / \mathrm{m}^{2}$ ) (Table 1). The former group displayed a reduced LBM according to all three definitions used (ALM/BMI $=1.11 \pm 0.14 \mathrm{vs}$. $0.85 \pm 0.14 ; p<0.01$; (ALM/weight) $\times 100=36.09 \pm 2.48$ vs. $27.86 \pm 3.34 ; p<0.01$ ) (Table 2), while the two groups were similar in age ( $31.26 \pm 12.68$ vs. $32.79 \pm 13.65$ years; $p=0.560)$ (Table 1$)$. According to the three definitions from low LBM, in the overweight and obesity groups, the prevalence varied between $23.6 \%$ and $69.4 \%$. None of the participants in the normal-weight group were affected by low LBM (Table 2).

Table 1. Anthropometric and sociodemographic characteristics of the study population.

\begin{tabular}{ccccc}
\hline & $\begin{array}{c}\text { Total Sample } \\
\mathbf{N}=\mathbf{1 1 0}\end{array}$ & $\begin{array}{c}\text { Normal Weight } \\
\boldsymbol{N}=\mathbf{3 8}\end{array}$ & $\begin{array}{c}\text { Overweight and Obesity } \\
\mathbf{N}=\mathbf{7 2}\end{array}$ & $\boldsymbol{p}$-Value \\
\hline Age (Years) & $32.26(13.28)$ & $31.26(12.68)$ & $32.79(13.65)$ & 0.560 \\
BMI & $29.76 \pm 7.28$ & $22.31 \pm 1.83$ & $33.69 \pm 5.85$ & $p<0.0001$ \\
Marital status & & & & 0.694 \\
Unmarried & $69(63.3)$ & $25(65.8)$ & $44(62.0)$ & \\
Married & $40(36.7)$ & $13(34.2)$ & $27(38.0)$ & 0.446 \\
Employment & & $13(34.2)$ & $30(41.7)$ & \\
Unemployed & $43(39.1)$ & $25(65.8)$ & $42(58.3)$ & \\
Employed & $67(60.9)$ & &
\end{tabular}

BMI: Body mass index. 
Table 2. Prevalence of reduced lean body mass (LBM) among the study participants using different definitions.

\begin{tabular}{|c|c|c|c|c|c|c|c|c|c|c|}
\hline \multirow{3}{*}{$\begin{array}{c}\text { Definition } \\
\text { of Low } \\
\text { LBM }\end{array}$} & \multirow{3}{*}{ Reference } & \multirow{3}{*}{$\begin{array}{l}\text { Cut-Off } \\
\text { Point }\end{array}$} & \multicolumn{5}{|c|}{ Low LBM } & \multicolumn{3}{|c|}{ Mean Values } \\
\hline & & & \multicolumn{2}{|c|}{$\begin{array}{l}\text { Normal Weight } \\
\qquad N=38\end{array}$} & \multicolumn{2}{|c|}{$\begin{array}{l}\text { Overweight and Obesity } \\
\qquad N=72\end{array}$} & \multirow[t]{2}{*}{$p$-Value } & \multirow[t]{2}{*}{$\begin{array}{l}\text { Normal } \\
\text { Weight } \\
N=38\end{array}$} & \multirow[t]{2}{*}{$\begin{array}{c}\text { Overweight } \\
\text { and Obesity } \\
\qquad N=72\end{array}$} & \multirow[t]{2}{*}{$p$-Value } \\
\hline & & & $\begin{array}{l}\text { Normal } \\
\text { LBM }\end{array}$ & $\begin{array}{l}\text { Low } \\
\text { LBM }\end{array}$ & $\begin{array}{l}\text { Normal } \\
\text { LBM }\end{array}$ & Low LBM & & & & \\
\hline ALM/BMI & Batsis et al. [14] & $<0.789$ & $\begin{array}{c}38 \\
(100.0)\end{array}$ & $0(0.0)$ & $50(69.4)$ & $22(30.6)$ & $<0.01$ & $1.11 \pm 0.14$ & $0.85 \pm 0.14$ & $<0.01$ \\
\hline \multirow{2}{*}{$\begin{array}{l}\text { ALM/Weight } \\
\times 100 \%\end{array}$} & $\begin{array}{l}\text { Levine and } \\
\text { Crimmins [15] }\end{array}$ & $<25.72$ & $\begin{array}{c}38 \\
(100.0)\end{array}$ & $0(0.0)$ & 55 (76.4) & 17 (23.6) & $<0.01$ & $36.09 \pm 2.48$ & $27.86 \pm 3.34$ & $<0.01$ \\
\hline & Oh et al. [16] & $<29.60$ & $\begin{array}{c}38 \\
(100.0)\end{array}$ & $0(0.0)$ & $22(30.6)$ & $50(69.4)$ & $<0.01$ & $36.09 \pm 2.48$ & $27.86 \pm 3.34$ & $<0.01$ \\
\hline
\end{tabular}

ALM: Appendicular Lean Mass.

The low LBM group had a higher prevalence of cardiometabolic diseases (36.0\% vs. $9.1 \%$; $p=0.019$ ) (Table 3). Moreover, the group with low LBM, when compared with the normal group, had a significantly higher BMI, waist-to-hip ratio, total body fat percentage, visceral fat mass, and fat-free mass percentage (Table 4).

Table 3. Prevalence of cardiometabolic disease among the sample study.

\begin{tabular}{|c|c|c|c|c|c|c|c|}
\hline \multirow[b]{2}{*}{ Disease } & \multirow[t]{2}{*}{$\begin{array}{c}\text { Total Sample } \\
\quad N=110\end{array}$} & \multirow[t]{2}{*}{$\begin{array}{c}\text { Normal } \\
\text { Weight } N=38\end{array}$} & \multirow[t]{2}{*}{$\begin{array}{l}\text { Overweight and } \\
\text { Obesity } N=72\end{array}$} & \multirow[t]{2}{*}{$p$-Value } & \multicolumn{2}{|c|}{$\begin{array}{l}\text { Overweight and } \\
\text { Obesity } N=72\end{array}$} & \multirow[t]{2}{*}{$p$-Value } \\
\hline & & & & & $\begin{array}{l}\text { Normal } \\
\text { LBM }\end{array}$ & $\underset{*}{\text { Low LBM }}$ & \\
\hline Type 2 diabetes & & & & $p=0.144$ & & & $p=0.804$ \\
\hline No & $105(96.3)$ & $37(100.0)$ & $68(94.4)$ & & $21(95.5)$ & $47(94.0)$ & \\
\hline Yes & $4(3.7)$ & $0(0.0)$ & $4(5.6)$ & & $1(4.5)$ & $3(6.0)$ & \\
\hline Dyslipidemia & & & & $p=0.008$ & & & $p=0.012$ \\
\hline No & $97(89.0)$ & $37(100.0)$ & $60(83.3)$ & & $22(100.0)$ & $38(76.0)$ & \\
\hline Yes & 12 (11.0) & $0(0.0)$ & $12(16.7)$ & & $0(0.0)$ & $12(24.0)$ & \\
\hline Cardiovascular & & & & & & & \\
\hline $\begin{array}{l}\text { Disease and } \\
\text { Hypertension }\end{array}$ & & & & $p=0.012$ & & & $p=0.093$ \\
\hline No & $98(89.0)$ & $37(100.0)$ & $61(84.7)$ & & $21(95.5)$ & $40(80.0)$ & \\
\hline Yes & $11(10.1)$ & $0(0.0)$ & $11(15.3)$ & & $1(4.5)$ & $10(20.0)$ & \\
\hline $\begin{array}{c}\text { Cardiometabolic } \\
\text { Disease }\end{array}$ & & & & $p=0.0004$ & & & $p=0.019$ \\
\hline No & 89 (81.7) & $37(100.0)$ & $52(72.2)$ & & 20 (90.9) & $32(64.0)$ & \\
\hline Yes & $20(18.3)$ & $0(0.0)$ & $20(27.8)$ & & $2(9.1)$ & $18(36.0)$ & \\
\hline
\end{tabular}

${ }^{*}$ Low LBM defined as ALM/weight $\times 100 \%<29.6$.

Table 4. Anthropometric characteristics and body composition patterns by BMI status and category of low LBM.

\begin{tabular}{|c|c|c|c|c|c|c|c|}
\hline & \multirow[b]{2}{*}{ Total $N=110$} & \multirow[b]{2}{*}{$\begin{array}{c}\text { Normal } \\
\text { Weight } N=38\end{array}$} & \multirow[b]{2}{*}{$\begin{array}{l}\text { Overweight and } \\
\text { Obesity } N=72\end{array}$} & \multicolumn{4}{|c|}{ Overweight and Obesity } \\
\hline & & & & $p$-Value & $\begin{array}{c}\text { Normal } \\
\text { LBM } N=49\end{array}$ & $\begin{array}{c}\text { Low LBM * } \\
N=23\end{array}$ & $p$-Value \\
\hline BMI & $29.76 \pm 7.28$ & $22.31 \pm 1.83$ & $33.69 \pm 5.85$ & $p<0.0001$ & $28.70 \pm 2.45$ & $35.88 \pm 5.57$ & $p<0.0001$ \\
\hline Waist to hip ratio & $0.92 \pm 0.06$ & $0.86 \pm 0.03$ & $0.95 \pm 0.04$ & $p<0.0001$ & $0.92 \pm 0.02$ & $0.97 \pm 0.03$ & $p<0.0001$ \\
\hline Total fat mass & $26.44 \pm 16.20$ & $11.02 \pm 3.40$ & $34.58 \pm 14.22$ & $p<0.0001$ & $21.28 \pm 4.98$ & $40.43 \pm 12.97$ & $p<0.0001$ \\
\hline$\%$ Body fat & $27.00 \pm 10.68$ & $16.03 \pm 4.57$ & $32.79 \pm 8.11$ & $p<0.0001$ & $23.94 \pm 4.30$ & $36.68 \pm 6.06$ & $p<0.0001$ \\
\hline Fat free mass & $64.10 \pm 11.75$ & $56.83 \pm 9.93$ & $67.93 \pm 10.83$ & $p<0.0001$ & $67.18 \pm 8.02$ & $68.26 \pm 11.91$ & $p>0.05$ \\
\hline$\%$ Fat-free mass & $72.54 \pm 11.47$ & $82.63 \pm 10.07$ & $67.21 \pm 8.11$ & $p<0.0001$ & $76.05 \pm 4.30$ & $63.32 \pm 6.07$ & $p<0.0001$ \\
\hline Visceral fat mass & $9.77 \pm 5.73$ & $3.97 \pm 1.65$ & $12.83 \pm 4.64$ & $p<0.0001$ & $8.23 \pm 2.05$ & $14.86 \pm 3.96$ & $p<0.0001$ \\
\hline Total body water & $47.19 \pm 8.02$ & $42.39 \pm 5.69$ & $49.72 \pm 7.94$ & $p<0.0001$ & $49.15 \pm 5.83$ & $49.97 \pm 8.75$ & $p>0.05$ \\
\hline ALM/weight $\times 100 \%$ & $30.70 \pm 4.98$ & $36.09 \pm 2.48$ & $27.86 \pm 3.34$ & $p<0.0001$ & $31.65 \pm 1.66$ & $26.19 \pm 2.37$ & $p<0.0001$ \\
\hline ALM/weight $\times 100 \%<29.6$ & & & & $p<0.0001$ & & & \\
\hline Normal LBM & $60(54.5)$ & $38(100)$ & $22(30.6)$ & & & & \\
\hline Low LBM & $50(45.5)$ & $0(0.0)$ & $50(69.4)$ & & & & \\
\hline
\end{tabular}

${ }^{*}$ Low LBM defined as ALM/weight $\times 100 \%<29.6$.

Logistic regression analysis showed that having low LBM increases the odds of having cardiovascular and metabolic diseases by nearly 555\% (OR $=5.46,95 \% \mathrm{CI}=1.31-26.39, p<0.05)$ after adding the total and visceral fat mass to the model (Table 5). 
Table 5. Odds of cardiometabolic diseases with reduced LBM among participants with overweight and obesity.

\begin{tabular}{cccc}
\hline & ALM $/ \mathbf{B M I}<\mathbf{0 . 7 8 9}$ & ALM $/$ weight $\times \mathbf{1 0 0} \%<\mathbf{2 5 . 7 2}$ & ALM $/$ weight $\times \mathbf{1 0 0} \% \mathbf{2 9 . 6}$ \\
\hline $\begin{array}{c}\text { Cardio-Metabolic } \\
\text { Diseases }\end{array}$ & & Odds $\mathbf{9 5} \% \mathbf{C I})$ & \\
\hline $\begin{array}{c}\text { LBM } \\
\text { No low LBM }\end{array}$ & 1.00 & 1.00 & 1.00 \\
Low LBM & $0.998(0.840-1.185)$ & $0.969(0.816-1.150)$ & $5.463(1.131-26.399)$ \\
$\begin{array}{c}\text { Percent visceral fat from } \\
\text { total fat }\end{array}$ & $2.204(0.656-7.408)$ & $1.421(0.377-5.359)$ & $0.976(0.832-1.145)$ \\
\hline
\end{tabular}

CI: Confidence interval.

\section{Discussion}

The present study aimed to provide preliminary data through a pilot study on the prevalence of low LBM in adult males with overweight and obesity and to assess any potential association between low LBM with cardiometabolic diseases, namely, type 2 diabetes, cardiovascular diseases and dyslipidemia, in this population. In turn, two major findings were revealed.

Firstly, in our population of men affected by overweight and obesity (across a wide age range), we found that the prevalence of low LBM was $23.6 \%, 30.6 \%$ and $69.4 \%$, respectively, based on the three definitions we used [14-16]. These fall within the wide prevalence range of 0 to $100 \%$ reported for males [20], however, using the same formulas, other studies reported different results. For instance, Stoklossa and colleagues found a higher prevalence of low LBM: $58.8 \%, 47.1 \%$ and $100 \%$, respectively. This variation may depend on the samples included. Specifically, in her study, participants with class II and III obesity (mean BMI $=44.0 \pm 6.3 \mathrm{~kg} / \mathrm{m}^{2}$ ) were included and they, logically, may have a high prevalence of low LBM. Our sample, conversely, included participants who were overweight, or of the class I and II obesity (mean BMI $=33.69 \pm 5.85 \mathrm{~kg} / \mathrm{m}^{2}$ ) categories [21]. In general, we speculate that higher prevalence tends to be in study samples accounting for body mass (i.e., weight and BMI) [20]. Furthermore, a low prevalence may also be explained by the use of definitions that have primarily been developed in the course of studies on older cohorts [20].

Second, we found that only one definition was able to detect any association between low LBM and cardiometabolic diseases [16]. Namely the definition proposed by Oh and colleagues [16] seems to be more clinically useful in detecting the association between low LBM and cardiovascular and metabolic diseases. In fact, nearly $36 \%$ of participants with low LBM had type 2 diabetes, cardiovascular disease or dyslipidemia, with these conditions strongly associated, where, low LBM increases the odds of presenting cardiometabolic diseases by more than $550 \%$ after adjusting for total body fat and central adiposity, which are known to be associated with cardiometabolic diseases.

Two clinical implications can be derived from our findings: Firstly, that an awareness of the high prevalence of reduced LBM in treatment-seeking adult males with overweight and obesity should be raised among clinicians as well as patients; secondly, our results reveal the importance of screening for low LBM in this population, since it seems to be strongly associated with cardiometabolic diseases.

Our study has certain strengths. Firstly, to the best of our knowledge, it is the first to assess low LBM in the Arab region and one of the few studies to assess low LBM among individuals with overweight and obesity, by taking into account ALM, weight and BMI [22]. In fact, as far as we are aware, only one study has used this definition to identify low LBM, in this case, among Italian treatment-seeking patients with obesity [13].

However, the study has certain limitations. First, our results need to be interpreted with caution because they may not apply to patients treated in other settings different from an outpatient clinic. Second, body composition was measured using a bio-impedance analyzer; despite being validated, it is still not accepted as the gold-standard technique for patients with overweight and obesity [23]. Third, no biochemical testing was conducted; this means that we are unable to shed any light on the mechanisms and implications of the sarcopenia that we observed in adult males with overweight and 
obesity. Fourth, by studying an exclusive male sample, our findings cannot be extended to females with obesity. Fifth, the cross-sectional design of our study should be considered as another limitation. Sixth, no objective measures regarding eating habits and levels of physical activity were available. Finally, in the diagnosis of cardiometabolic diseases, we relied on self-reporting data.

\section{Conclusions}

Our findings provide evidence that adult males with overweight and obesity who are seeking treatment have a high prevalence of low LBM. This condition seems to be strongly associated with the presentation of weight-related diseases, such as cardiovascular disease, type 2 diabetes and dyslipidemia. Therefore, the identification of low LBM in this population is clinically useful.

Author Contributions: All authors claim authorship and have approved and made substantial contributions to the conception, drafting and final version of the paper. The study was designed by M.E.G., while L.I. conducted the statistical analysis. S.K., D.K., D.E.M. and H.T. collected data. M.E.G., L.I. and R.C. co-wrote the manuscript.

Funding: The authors received no funding.

Conflicts of Interest: There is no conflict of interest to report.

\section{References}

1. Silver, H.J.; Welch, E.B.; Avison, M.J.; Niswender, K.D. Imaging body composition in obesity and weight loss: Challenges and opportunities. Diabetes Metab. Syndr. Obes. 2010, 3, 337-347. [CrossRef] [PubMed]

2. Das, S.K. Body composition measurement in severe obesity. Curr. Opin. Clin. Nutr. Metab. Care 2005, 8, 602-606. [CrossRef] [PubMed]

3. Hioki, H.; Miura, T.; Motoki, H.; Kobayashi, H.; Kobayashi, M.; Nakajima, H.; Kimura, H.; Mawatari, E.; Akanuma, H.; Sato, T.; et al. Lean body mass index prognostic value for cardiovascular events in patients with coronary artery disease. Heart Asia 2015, 7, 12-18. [CrossRef] [PubMed]

4. Kalyani, R.R.; Tra, Y.; Egan, J.M.; Ferrucci, L.; Brancati, F. Hyperglycemia is associated with relatively lower lean body mass in older adults. J. Nutr. Health Aging 2014, 18, 737-743. [CrossRef] [PubMed]

5. Kim, K.; Park, S.M. Association of muscle mass and fat mass with insulin resistance and the prevalence of metabolic syndrome in Korean adults: A cross-sectional study. Sci. Rep. 2018, 8, 2703. [CrossRef] [PubMed]

6. Pichard, C.; Kyle, U.G.; Morabia, A.; Perrier, A.; Vermeulen, B.; Unger, P. Nutritional assessment: Lean body mass depletion at hospital admission is associated with an increased length of stay. Am. J. Clin. Nutr. 2004, 79, 613-618. [CrossRef] [PubMed]

7. Szulc, P.; Munoz, F.; Marchand, F.; Chapurlat, R.; Delmas, P.D. Rapid loss of appendicular skeletal muscle mass is associated with higher all-cause mortality in older men: The prospective MINOS study. Am. J. Clin. Nutr. 2010, 91, 1227-1236. [CrossRef]

8. Srikanthan, P.; Horwich, T.B.; Tseng, C.H. Relation of Muscle Mass and Fat Mass to Cardiovascular Disease Mortality. Am. J. Cardiol. 2016, 117, 1355-1360. [CrossRef]

9. Fukushima, Y.; Kurose, S.; Shinno, H.; Cao Thu, H.; Takao, N.; Tsutsumi, H.; Kimura, Y. Importance of Lean Muscle Maintenance to Improve Insulin Resistance by Body Weight Reduction in Female Patients with Obesity. Diabetes Metab. J. 2016, 40, 147-153. [CrossRef]

10. Kreidieh, D.; Itani, L.; El Masri, D.; Tannir, H.; Citarella, R.; El Ghoch, M. Association between Sarcopenic Obesity, Type 2 Diabetes, and Hypertension in Overweight and Obese Treatment-Seeking Adult Women. J. Cardiovasc. Dev. Dis. 2018, 5, 51. [CrossRef]

11. Peppa, M.; Koliaki, C.; Boutati, E.; Garoflos, E.; Papaefstathiou, A.; Siafakas, N.; Katsilambros, N.; Raptis, S.A.; Hadjidakis, D.I.; Dimitriadis, G.D. Association of lean body mass with cardiometabolic risk factors in healthy postmenopausal women. Obesity 2014, 22, 828-835. [CrossRef] [PubMed]

12. Barazzoni, R.; Bischoff, S.; Boirie, Y.; Busetto, L.; Cederholm, T.; Dicker, D.; Toplak, H.; Van Gossum, A.; Yumuk, V.; Vettor, R. Sarcopenic Obesity: Time to Meet the Challenge. Obes. Facts 2018, 11, $294-305$. [CrossRef] [PubMed]

13. El Ghoch, M.; Rossi, A.P.; Calugi, S.; Rubele, S.; Soave, F.; Zamboni, M.; Chignola, E.; Mazzali, G.; Bazzani, P.V.; Dalle Grave, R. Physical performance measures in screening for reduced lean body mass in adult females with obesity. Nutr. Metab. Cardiovasc. Dis. 2018, 28, 917-921. [CrossRef] [PubMed] 
14. Batsis, J.A.; Mackenzie, T.A.; Lopez-Jimenez, F.; Bartels, S.J. Sarcopenia, sarcopenic obesity, and functional impairments in older adults: National Health and Nutrition Examination Surveys 1999-2004. Nutr. Res. 2015, 35, 1031-1039. [CrossRef] [PubMed]

15. Levine, M.E.; Crimmins, E.M. The impact of insulin resistance and inflammation on the association between sarcopenic obesity and physical functioning. Obesity 2012, 20, 2101-2106. [CrossRef] [PubMed]

16. Oh, C.; Jho, S.; No, J.K.; Kim, H.S. Body composition changes were related to nutrient intakes in elderly men but elderly women had a higher prevalence of sarcopenic obesity in a population of Korean adults. Nutr. Res. 2015, 35, 1-6. [CrossRef] [PubMed]

17. Expert Panel on Detection, Evaluation, and Treatment of High Blood Cholesterol in Adults. Executive Summary of The Third Report of The National Cholesterol Education Program (NCEP) Expert Panel on Detection, Evaluation, And Treatment of High Blood Cholesterol In Adults (Adult Treatment Panel III). JAMA 2001, 285, 2486-2497. [CrossRef]

18. Faul, F.; Erdfelder, E.; Lang, A.G.; Buchner, A. G*Power 3: A flexible statistical power analysis program for the social, behavioral, and biomedical sciences. Behav. Res. Methods 2007, 39, 175-191. [CrossRef]

19. Bredella, M.A.; Ghomi, R.H.; Thomas, B.J.; Torriani, M.; Brick, D.J.; Gerweck, A.V.; Misra, M.; Klibanski, A.; Miller, K.K. Comparison of DXA and CT in the assessment of body composition in premenopausal women with obesity and anorexia nervosa. Obesity 2010, 18, 2227-2233. [CrossRef]

20. Johnson Stoklossa, C.A.; Sharma, A.M.; Forhan, M.; Siervo, M.; Padwal, R.S.; Prado, C.M. Prevalence of Sarcopenic Obesity in Adults with Class II/III Obesity Using Different Diagnostic Criteria. J. Nutr. Metab. 2017, 2017, 7307618. [CrossRef]

21. Rothney, M.P.; Brychta, R.J.; Schaefer, E.V.; Chen, K.Y.; Skarulis, M.C. Body composition measured by dual-energy X-ray absorptiometry half-body scans in obese adults. Obesity 2009, 17, 1281-1286. [CrossRef] [PubMed]

22. Studenski, S.A.; Peters, K.W.; Alley, D.E.; Cawthon, P.M.; McLean, R.R.; Harris, T.B.; Ferrucci, L.; Guralnik, J.M.; Fragala, M.S.; Kenny, A.M.; et al. The FNIH sarcopenia project: Rationale, study description, conference recommendations, and final estimates. J. Gerontol. A Biol. Sci. Med. Sci. 2014, 69, 547-558. [CrossRef] [PubMed]

23. Coppini, L.Z.; Waitzberg, D.L.; Campos, A.C. Limitations and validation of bioelectrical impedance analysis in morbidly obese patients. Curr. Opin. Clin. Nutr. Metab. Care 2005, 8, 329-332. [CrossRef] [PubMed] 